\title{
Erken çocukluk eğitiminde düşünmeyi görünür kılmak: Görünür düşünme yaklaşımı
}

\section{Making thinking visible in early childhood education: Visible thinking approach}

\begin{abstract}
Makale Geçmişi
Geliş : :03 Ocak 2019

Düzeltme : 08 Subat 2019

Kabul : 10 Şubat 2019

Çevrimiçi : 20 Mart 2019
\end{abstract}

Makale Türü

Derleme Makale

\section{Article History}

Received : 03 January 2019 Revised : 08 February 2019 Accepted : 10 February 2019 Online : 20 March 2019

Article Type

Revien Article

\author{
Sadiye Keleş ${ }^{1}$, Özlem Yurt ${ }^{2}$
}

\begin{abstract}
Öz: Düşünmenin öğretilmesine ilişkin çabalar uzun yıllardır devam etmektedir. Son yllarda bilimsel araştırmalardan elde edilen bulgular, özellikle öğretmenlerin sahip oldukları çeşitli özelliklerin, düşünmeyi öğretme konusunda kritik değere sahip olduğunu kanıtlamıştır. Bu özellikleri; öğretmenlerin öğretim faaliyetlerinde benimsediği yaklaşımlar, öğretim stratejileri (bireysel ya da iş birliğine dayalı etkinlik tercihleri), sınıf yönetimi yaklaşımları ve düşünmeyi öğretme konusundaki öz-yeterlilik düzeyleri olarak sıralamak mümkündür. Düşünme doğası gereği soyuttur; çocukların düşünme süreçlerinin açık ve izlenebilir hale getirilmesi, hem çocukların kendi öğrenme süreçlerini takip edebilmesi hem de okul ortamında düşünme kültürünün inşa edilmesi açısından önemli görülmektedir. Bu noktada öğretmenlere, çocukların düşünme süreçlerini somutlaştırmalarını sağlayacak çeşitli eğitsel uygulamalar gerçekleştirmelerine yönelik farklı yöntem ve stratejilerin sunulması bu süreci destekleyecektir. Bu çalışmada düşünmenin, çocuk ile etkileşim halindeki tüm bireyler (diğer çocuklar, öğretmenler ve aileler gibi) için görünür olmasını hedefleyen, kısa, tekrarlanabilir, esnek mini stratejiler olan ve Düşünme Rutinleri’nin kullanımını hedefleyen Görünür Düşünme Yaklaşımı hakkında detaylı bilgiler sunulmuştur. Harvard Üniversitesi'nde başlatılmış olan Project Zero' nun alt projelerinden yalnızca biri olan Görünür Düşünme Yaklaşımı, kişilerin düşünme eğilimlerini harekete geçirecek ve onları düzenleyecek, her eğitim kademesinde kullanılabilen, tekrarlanabilir ve esnek bir öğrenme - öğretme yaklaşımıdır. Bu yaklaşım ile gerçekleştirilen düşünme rutinleri ile okul ya da sinıflarda düşünme kültürünün gelişimini destekleyici çeşitli rutinlere ilişkin sınıf içi örnek uygulamalara yer verilmiştir. Bu uygulamalardan bazılar1; Bunu Neden Söylüyorsun?, Düşün/Bul/Keşfet, Düşün/Eşleş/Paylaş, Eskiden............. Düşünürdüm/Şimdi......Düşünüyorum, Bak/Düşün/Merak Et, Pusula Noktaları, Başlangıç/Orta/Son ve Yakınlaștır'dır.
\end{abstract}

Anahtar Kelimeler: Project Zero, Görünür Düşünme, Erken çocukluk, Düşünme araçları, Düşünme rutinleri

Abstract: Efforts to teach thinking have been continuing for many years. In recent years, the findings from scientific research have proved that especially the various characteristics of teachers have a critical value in teaching thinking. These features; it is possible to list teachers' approaches to teaching activities, instructional strategies (individual or collaborative activity preferences), classroom management approaches and self-efficacy levels in teaching thinking. Thinking is inherently abstract; making children's thinking processes clear and traceable is considered important both for children to follow their own learning processes and to build a culture of thinking in the school environment. At this point, the introduction of different methods and strategies for teachers to implement various educational practices that will enable children to embody the processes of thinking will support this process. In this study, detailed information about the Visible Thinking Approach, which is aimed at the use of Thinking Routines, which are short, reproducible, flexible mini strategies that aim to make thinking visible to all individuals (like other children, teachers and families) interacting with the child, are presented. Only one of the sub-projects of Project Zero, which was launched at Harvard University, Visible Thinking Approach is a reproducible and flexible learning-teaching approach that can mobilize and organize people's thinking tendencies and can be used in every education level. With this approach, in-class sample practices related to various routines that support the development routines and the development of thinking culture in schools or classrooms are included. Some of these applications; What Makes You Say That? Think/Puzzle/Explore, Think/Pair/Share, I used to think..../Now I think..., See/Think/Wonder, Zoom in, Beginning / Middle / End and Compass Points.

Keywords: Project Zero, Visible Thinking, Early childhood, Tools for thinking, Routine for thinking

DOI: $\underline{10.24130 / \text { eccd-jecs.1967201931124 }}$ 


\section{SUMMARY}

Children need to interact with their environment in order to understand and learn the world around them. The knowledge acquired through thinking and experience is gained by progressing through various cognitive process stages. One of the concepts that are important in direction and development of cognitive processes is thinking. The importance of the 'concept of thinking' is increasing with the findings obtained from scientific researches. Although this concept includes a wide range of development from birth, teaching in early childhood is emphasized by different theorists and approaches. The most widely accepted theorists of the past works on how children think are Piaget (and his colleague Inhelder), Vygotsky (and his colleague Luria) and Bruner.

Project Zero, one of the current studies on this subject, is a research project aimed to understand the learning through art initiated in 1967 by philosopher Nelson Goodman of Harvard University. Researchers involved in the project have brought together a number of different disciplinary perspectives. Nowadays, the project research team continues to measure the effects of training programs from early childhood education to high school. One of these researches is the Visible Thinking Approach. According to this approach, learning takes place as a result of thinking.

The Visible Thinking Approach is an approach that aims to advance children's thinking skills, encourage thinking, and make thinking visible. Any observable concrete representations that document the development of children's questions, thoughts, and interpretations with visible thinking can be obtained. Through this documentation, teachers can enable children to participate by using thinking routines, which are short and mini-strategies that develop and deepen the deep thinking of children. There are many (more than 30) thinking routines available for each educational level in Project Zero's publications.

Thinking routines affect the cognitive, social and emotional development of children and affect their motivation and increase their participation in the activities. These routines will provide the formation of thinking culture in the classroom as it is used as a strategy in activities. In the provision of thinking culture and a climate of thinking in the classroom, it would be useful for teachers to incorporate their thinking processes into learning processes.

Thinking routines and documentation are effective tools in the development of children's thinking in developing their thoughts and in this way, in the development of cognitive development, creative and critical thinking. With routines, teachers provide tools for planning learning processes, gaining a new concept or theme, producing possibilities and alternatives, discussing thoughts and evaluating actions, and determine assumptions and prejudices. The effectiveness of thinking routines is related to the presentation of images to children, to directing visuals to stimulate their curiosity and to collecting and recording data from children during practices. Materials such as dialogues, speeches, graphics, drawings, photographs, films or sound 
recordings that will be recorded through documentation during routines will inform children about what they know and how they reflect their thoughts.

There are various routines to support the development of thinking culture in schools or classes with thinking routines performed with this approach; What Makes You Say That?, Think/Puzzle/Explore, Think/Pair/Share, I used to think..../Now I think..., See/Think/Wonder, Zoom in, Beginning / Middle / End and Compass Points. These routines help teach children to think critically and to encourage them to use their imagination in order to identify the information they have observed and to have a connection with their previous knowledge, evoking curiosity, encouraging them to think about a problem, a question or a theme, reflecting their thoughts, and investigating how and why this idea changes,

As a result, the multidimensional structure of thinking, based on different theoretical structures, continues to be tested with various educational practices with different dimensions. In Turkey, especially in recent years, studies on the development of thinking skills in early childhood, teaching methods that are effective in thinking development, teacher opinions and practices on thinking skills are gaining speed.

In the context of the results obtained from these studies, using short, repeatable, flexible mini-strategies that aim to make thinking visible to people and teachers working with children, thinking routines as a means of thinking, using it as a tool of thinking and providing sample applications for the use of these routines will contribute to the "reflective" characteristics of teachers as well as creating thinking in children. If teachers use their thinking routines as part of their daily educational flow and to include documentation practices systematically and in the evaluation processes of the child in all areas of development, will be an important step in teaching thinking. 


\section{GİRIŞ}

"Düşünmeyi öğretme” son y1llarda oldukça çeşitli disiplinler (hukuk gibi) için ilgi çeken konu başlıklarından biri haline gelmiştir. Aslında “çocukların düşüncelerini geliştirme fikri, günümüzden Plato'ya kadar var olan eğitim geleneğinin iz bırakan ve iddialı çabalarından biridir (Swartz ve Perkins, 1990). De Bono'ya (1991, s. 33) göre "Düşünme, bir amaç için kasıtlı bir deneyim keşfi’dir. Bu amaç, anlama, karar verme, planlama, problem çözme, yargılama, eylemde bulunma gibi çeşitli süreçleri ya da becerileri içermektedir. Düşünmenin çok boyutlu bir yapıya sahip olması nedeniyle "düşünmeyi öğretme"nin de birçok yönü vardır. Bu nedenle düşünmeyi öğretme çabaları farklı yaklaşımlar ve araştırmacılar tarafından çeşitli şekillerde vurgulanmıştır. Genel anlamıyla düşünmeyi öğretme, bir probleme çözüm üretme üzerine vurgu yaparak esnek öğrenmenin gelişimi ile ilişkili olma eğilimine işaret etmektedir. Eğitimin ve eğitim programlarının tüm alanları aracıllğ̆ıla belirli becerilerin ve stratejilerin uygulanmasını teşvik eden bir düşünme eğitim programıyla, ayrı bir program veya telkin olarak düşünmenin nasıl öğretileceği konusunda henüz bir fikir birliği yoktur. $\mathrm{Bu}$ nedenle düşünmeyi öğretmek için en uygun yaşın hangi yaş olduğu konusunda henüz kesinleşmiş bir öneri bulunmamaktadır (Aubrey, Ghent ve Kanira, 2012).

Ancak düşünmenin gelişimsel doğasının nasıl seyrettiğine ilişkin bilimsel görüşler, düşünmeyi öğretmenin başlangıç noktası hakkında fikir sunabilmektedir. Düşünme gelişimine yönelik geçmiş çalışmalar üzerinde oldukça güçlü etkisi olan araştırmacılar hiç kuşkusuz ki Piaget (ve çalışma arkadaşı Inhelder), Vygotsky (ve çalışma arkadaşı Luria) ve Bruner'dir (Halford, 2005). Piaget, çocukları etkin ve yapılandırmacı düşünürler olarak görmektedir. Çocuklar için farklı gelişim evrelerinde farklı düşünme becerilerinden bahsederek, bunların bir düzen içinde geliştiği ve birbirinden nitelik olarak da farklı olduklarını vurgulamaktadır (Öktem, 2018). Aynı zamanda çocukların fiziksel nedenselliği kavrayışları, rüyaları kavrayışları ve ahlakı kavrayışları gibi çok geniş bir alanda gözlemler gerçekleştirmiştir (Gelman ve Frazier, 2012). Vygotsky ise, biyolojik olgunlaşma ve sosyal deneyim arasındaki etkileşimi vurgulamaktadır. Çocuk olgunlaştıkça dil (bu anlamda semboller), düşünce gelişiminde giderek daha önemli bir etkiye sahip olmaktadır. Vygotsky'nin bilim dünyasına en büyük katkılarından biri düşünce gelişiminde kültürün (kültürel sembollerin ve çocuğun sosyal çevresinde yer alan ve düşünmeye aracılık eden diğer bireylerin) rolü üzerine yaptığı vurgudur (Halford, 2005). Bruner'e göre ise düşünme, deneme ve bulmaya dayalı olan buluş yoluyla öğrenmenin gerçekleşeceğidir. Bu yolla çocuklar düşünme, deneme, tekrar deneme, keşfetme ve bulmaya dayalı olarak, bilim insanlarının çalışmalarına benzer şekilde kendi kendilerine öğrenmelerini gerçekleştirirler (Çakıc1, 2010). 
Günümüzde eğitimciler, giderek artan akademik beklentileri karşılamak için okur-yazarlık ve matematik becerilerini geliştirmeye odaklansalar da daha geniş düşünme becerilerini geliştirmeyi de hedefleri arasına almaları gerekmektedir. Çocuklar, sınıf ortamında düşünme iklimine alt yap1 sağlanmasıyla, karar vermeyi, kendi davranışlarını düzenlemeyi, karmaşık zorluklarla başa çıkabilmeyi ve eylemlerinden sorumlu olmayı içselleştirebilirler. Hiç kuşkusuz sınıf ortamında düşünme ikliminin oluşturulmasında temel faktörlerden biri öğretmenlerin yaklaşımlarıdır.

\section{Düşünme İklimi ve Öğretmen Desteği}

Açık-uçlu soruların sorulması, rekabete dayalı uygulamalar yerine iş birliğini destekleyen uygulamaların yapılması, çocukların performanslarının birbirleriyle karşılaştırılmasından kaçınılması, bir beceriyi ortaya koymalarından çok ilerlemeleri üzerine odaklanılması, çocukların kendilerini güvende hissetmesi ve öğretmenler için sınıf yönetimini kolaylaştırmasının yanı sıra sınıf ortamında düşünme iklimi oluşturmak açısından kritik değere sahiptir. Sınıf ortamında düşünme ikliminin oluşturulmasında, olumlu sınıf yönetiminin ve çocuklar arası olumlu etkileşimin sağlanması tek başına yeterli olmamaktadır: Düşünme ikliminin sağlanmasında, öğretmenlerin etkili öğretim uygulamalarını gerçekleştirmesi tamamlayıcı bir unsur olarak değerlendirilmektedir. Etkili öğretmenler, ele alınan temanın ya da kazanımın derin öğrenme yoluyla kazanılması için temel öğretim stratejilerinin ilerisine giderek düşünme süreçlerini de etkinliklerine dahil edebilirler (Eggen ve Kauchak, 2006, s.72-76). Örneğin düşünmeyi öğretmede kolaylaştırıc1 role sahip öğretmenlerin, çocukların kazanımlarını destekleme açısından daha etkili sonuçlara ulaşılmasında anlamlı bir etkiye sahip olduğu kanıtlanmıştır (Dilekli ve Tezci, 2016). Buna karşın, düşünme sürecinin öğretim uygulamalarına dahil edilmesinin önünde birtakım engeller olduğu, son yıllarda gerçekleştirilen araştırmalarla ortaya konmuştur. Dilekli ve Tezci (2016), öğretmenlerin öz-yeterlilik algılarının, düşünmeyi öğretme uygulamaları açısından anlamlı bir değişken olduğunu saptamıştır. Öğretmenlerin düşünmeyi öğretme açısından akademik yetkinlikte (Aslan, 2017; Baysal, Çarıkçı ve Yaşar, 2017) ve düşünmeyi öğretmeye ilişkin etkinlik tasarlamada, uygulama basamağına göre daha düşük seviyede olduğu saptanmıştır (Aslan, 2017). Benzer şekilde öğretmenlerin ağırlıklı olarak bilgi düzeyinde soru sordukları, üst bilişsel düzeyde çok az soru sordukları ve değerlendirme düzeyinde ise soru sormadıkları belirlenmiştir (Bay ve Alisinanoğlu, 2012). Ayrıca öğretmenlerin üst düzey düşünme ve düşünmenin aktarımına (transferine) yönelik öz-yeterliliklerinin düşük olduğu tespit edilmiştir (Tebbs, 2000).

Sınıf öğretmenleri ile gerçekleştirilen nitel bir araştırmada ise, öğretmenlerin düşünme becerilerinin kazandırılmasında öğretmen, çocuk, program ve materyal boyutu olmak üzere geniş bir alanda 
sorunlar yaşadıkları saptanmıştır. Ancak bulgular incelendiğinde öğretmen boyutunun ve çocuk boyutunun eş alt kategori olarak sinıflanabileceğine yönelik ifadeler göze çarpmaktadır: Öğretmenlerin, öğretmen boyutunda düşünme becerilerinin geliştirilmesinde bilgi eksikleri olduğuna vurgu yaptıkları, çocuk boyutunda ise özellikle çocukların gelişim seviyelerine uygun tasarılar gerçekleştirmekte ve çocukların hayal güçlerini ve meraklarını kışkırtmakta güçlük çektiklerine işaret ettikleri görülmektedir (Baysal ve diğerleri, 2017). Bu noktada Görünür Düşünme Yaklaşımı'nın, ortaya koyduğu pratik, kolay öğrenilebilir, tekrarlanabilir, esnek uygulama yapısına sahip mini stratejilerle (düşünme rutinleri ile), öğretmenlere sınıflarında düşünme iklimi yaratma ve tasarladıkları etkinliklere düşünme süreçlerini dahil etme firsatı sunacağı ve böylece öğretmenlerin akademik yetkinliklerinin artacağı, etkinlik tasarılarına düşünme süreçlerini dahil etmede sahip oldukları düşük puanların, uygulamaları önünde bir engel olmaktan çıkacağı düşünülmektedir. Aşağıda, Görünür Düşünme Yaklaşımı'na ilişkin detaylı bilgiye yer verilmiştir.

\section{Project Zero ve Görünür Düşünme Yaklaşımı}

Project Zero, 1967 yllinda, bir sanat eğitimi projesi olarak Harvard Üniversitesi'nden Nelson Goodman tarafından başlatılan ${ }^{1}$ ve insanların sembolik gelişimlerini disiplinlerarası bir yaklaşım ile temellendiren bir araştırma projesinin adıdır. Projeye dahil olan araştırmacılar insanların sembolik gelişimlerini incelerken bilişsel psikoloji (Jean Piaget), Gestalt psikolojisi (Rudolf Arnheim) ve gelişim psikolojisi (Sigmund Freud, Otto Rank); semiyoloji; dilbilim (Claude Levi-Strauss); felsefe (Nelson Goodman); eğitim ve sanat olmak üzere çok sayıda disiplinin geniş boyutlu verilerini kullanmış ve bu verilerin bir sentezi olarak projeyi şekillendirmişlerdir (Perkins ve Gardner, 1988; Rush ve Lovano-Kerr, 1982).

Projenin ilk amacı, sanat felsefesini ve psikolojisini, özellikle dil, yazı, resimleme, jest, sembolik oyun gibi çeşitli simge sistemleri ile açıklamaya çalışmaktır (Perkins ve Gardner, 1988). Project Zero 1970'lerde, David Perkins ve Howard Gardner'in eşbaşkanlığında, psikolojik konulara daha fazla eğilmiştir. Bu süreçte Perkins, temel odağı yetişkinlerin algisal ve bilişsel kapasiteleri olan bir "Bilişsel Beceri Grubu"nu yönetirken; Gardner, normal gelişim gösteren ve üstün yetenekli çocuklarda sembol kullanım becerilerinin geliştirilmesine odaklanan bir "Gelişim Grubu"na yön vermiştir (Gardner, 1989). Bu gruplar da çeşitli alt projeler (GoodWork, Visible Thinking gibi) üzerine çalışarak, çeşitli çalışma takımları oluşturmuştur (Ritchhart, Palmer, Church ve Tishman, 2006). Sanat ve eğitim odaklı başlamış olan Project Zero'nun çalışma ekiplerinden bazıları,

\footnotetext{
${ }^{1}$ Goodman, Charles Sanders Peirce (1940), Ernst Cassirer (1953-1957) ve Susanne Langer (1942), tarafindan gerçekleştirilen daha önceki girişimleri takiben projeyi şekillendirmiştir (Gardner, 1989).
} 
çocukların resim algıları ve edebi metafor anlayışını incelemek için boylamsal, gelişimsel ve kesitsel araştırmalar gerçekleştirmişlerdir. Proje çalışma grupları, halen, okul öncesi eğitimden lise düzeyine kadar eğitim programlarında uygulanan çalışmaların etkiliğine ilişkin analizlerini gerçekleştirmeye devam etmektedir (Gardner, 1989, Rush ve Lovano-Kerr, 1982; Perkins ve Gardner, 1988). Bu süregelen incelemelerden biri de Görünür Düşünme Yaklaşımı (Visible Thinking-GDY) üzerinedir.

GDY, çocukların düşünme becerilerini ve eğilimlerini geliştirme ve herhangi bir içerik alanındaki öğrenmeyi derinleştirmeyi amaçlayan bir yaklaşımdır (Visible Thinking, 2018). GDY’ye göre öğrenme, temelde düşünmenin sonucudur. Düşünmeyi teşvik etmek, düşünceyi görünür kılmay1 gerektirir. Etkili düşünme, yalnızca bir beceri ile ilgili değil, aynı zamanda eğilimlerle de ilgilidir. Düşüncenin gelişimi sosyal/toplumsal bir çabadır, bu nedenle sınıf kültürü, öğrenilen öğeleri belirler ve öğrenilenleri şekillendirir. Düşüncenin görünür hale getirilmesi hem çocuklar hem de öğretmenler tarafından açık, bilinçli ve kasıtlı eylemler gerektirir. Bu nedenle okullar, öğretmenler için de düşünme kültürüne sahip olan kurumlar haline getirilmelidir (Hull, Balka ve Miles, 2011; Ritchhart ve Perkins, 2008).

Genellikle, bir çocuğun düşüncesi diğer çocuklar, öğretmenler ve hatta kendileri için görünmezdir, çünkü insanlar genellikle nasıl düşündükleri hakkında pek az şey düşünürler. Düşünme görünür olduğunda ise, çocukların ilgisi, katılımları ve motivasyonları artmakta, önceki bilgilerle yeni bilgiler arasında bağlantı kurma ve derin düşünme için olanakları çeşitlenmekte, katılımcılar kendi düşünce ve düşünce süreçlerinin yanı sıra birlikte çalıştıkları kişilerin de farkına vardıkları için sınıf içi etkileşim artmakta, çocukların kendi gelişimleri ve öğrenmeleri için sorumluluk alması teşvik edilmektedir. Ayrıca öğretmenler yalnızca düşünmeyi görünür hale getirerek, çocukların neyi ve nasıl öğrendiklerine ilişkin etkili gözlemler yapabilme şansına sahip olabilmektedirler. Yapıları, rutinleri, soruları derinlemesine araştırarak ve belgeleri kullanarak, çocukların düşünmelerini daha görünür hale getirebilir, daha etkili düşünmeyi ve derin öğrenmeyi teşvik edebilirler (Ritchhart, 2015, s.315).

GDY, öğretmenlere, çocukların düşünmelerini genişleten, derinleştiren ve günlük sınıf hayatının yapısının bir parçası olan, kısa, öğrenmesi kolay, mini stratejiler olan Düşünme Rutinleri ve belgeleme aracilığıla çocukların düşünme etkinliklerine katılmalarını sağlar. Bu yönüyle, her an biçimlendirici değerlendirme yoluyla geri bildirim verme şansı sunar (Salmon, 2008; Hull ve diğerleri, 2011).

GDY’nın, eğitim ortamı içinde ilkelerine uygun bir şekilde uygulanabilmesinde; düşünce sürecini sınıfta doğal, yönetilebilir bir şekilde daha görünür kılmak için çocuklar veya öğretmenler tarafından 
şekillendirilebilen ve esnek bir yapıya sahip düşünme rutinleri kullanılmaktadır. Öğretmenler, rutinleri kullanırken veya bir ideali araştırırken çocukların oluşturduğu ürünler veya belgeler üzerine düşünürler. Çocuklar tarafından oluşturulan resimlemeler, çizimler, 3-boyutlu ürünler, listeler, haritalar, çizelgeler, diyagramlar ve çalışma sayfaları gibi belgeler, çocukların düşünme süreçlerinin anlaşılması konusunda öğretmene çeşitli ipuçları sunmaktadır (Visible Thinking, 2018).

Project Zero'nun yayınlarında, her eğitim kademesi için kullanılabilecek çok sayıda (30'dan fazla) düşünme rutini mevcuttur. Aşağıda, Düşünme Rutinleri'nin genel yapısından bahsedilmiş, erken çocukluk dönemi için kullanılabilecek birkaç düşünme rutini detaylı olarak sunulmuş ve çeşitli uygulama örneklerine yer verilmiştir.

\section{Görünür Düşünme Yaklaşımı'nın Araçları: Düşünme Rutinleri}

İnsanlar günlük hayatlarını çok çeşitli rutinler çerçevesinde sürdürürler. Uyanma ve uyuma zamanı gibi düşünmeden yapılan ve performansın otomatikliği anlamını taşıyan bilinçaltı rutinleri olduğu gibi; kişiler tarafindan kasıtlı olarak tekrarlanan ya da öğrenilen, görece günlük hayatta daha az sıklıkta gerçekleştirilen ya da yeni kazanılan rutinler olan diğer rutinler örnek olarak sunulabilir (Chang, 2004; Wildenger ve diğerleri 2008). Rutinler açıkça öğretildiğinde, modellendiğinde ve tekrar edildiğinde, insanlar için otomatik hale gelirler. $\mathrm{Bu}$ önemlidir, çünkü rutinlerin otomatikleşmesi, bireyin bilişsel işleme alanının serbest kalmasını sağlar. Dolayısıyla bu otomatikleşme bireylerin bilişsel alanlarının daha etkili bir şekilde işlemesi açısından bir zemin oluşturur (Leinhardt, Weidman ve Hammond, 1987). Bu bağlamda rutinlerin eğitim ortamının bir parçası haline getirilmesi oldukça önemlidir.

Rutinler, küçük çocuklarda yeni beceriler edinmek için anlamlı dizileri oluşturmaktadır. Bunlar tahmin edilebilir ve işlevseldir, ayrıca gün içinde birçok kez ortaya çıkarlar (Woods, Kashinath ve Goldstein, 2004). Eğitim ortamında kullanılan çeşitli rutinlerin çocukların duygusal ve sosyal gelişimlerinin yanı sıra bilişsel gelişimleri üzerinde doğrudan etkili olduğu (Ostrosky, Jung, Hemmeter ve Thomas, 2003), çocukların motivasyonlarını arttırarak etkinliğe dahil olma düzeylerini arttırdığı (Wright, 2014), davranış problemlerini indirgediği (Ostrosky ve diğerleri, 2003) bilinmektedir. Öğretmenlerin rutin kullanımı yalnızca çocuklara güven hissi vermek değil, aynı zamanda düşünme kültürü geliştikçe zihin alışkanlıkları yaratmak açısından da önemlidir (Ritchhart, 2002).

Ayrıca eğitim ortamları için çeşitli sınıf rutinleri oluşturmak iletişimi, öğrenmeyi ve düşünmeyi kolaylaştırır. Örneğin Watson ve DiCarlo (2016), 7 aydır okula devam eden ancak, çok basamaklı 
günlük sınıf rutinlerini takip etmekte zorluk çeken bir çocuğun bulunduğu sınıfta, bir haftada 5 gün uygulanabilecek şekilde bir Resim Etkinliği Programı'nı gerçekleştirmiştir. Resim Etkinliği Programı, sınıfta uygulanan her üç rutin (sabah, yemek zamanı ve akşam üstü rutinleri) için hikaye şeridi formunda düzenlenmiş görsellerden oluşmuştur. Hikaye şeridi formunda görsellerde, ilgili rutinde çocuk tarafından gerçekleştirilmesi beklenen her bir davranış adım adım ifade edilerek resimsel olarak dizginlenmiştir. Araştırma sonucunda, günlük sınıf rutinlerini takip etmekte zorluk çeken çocuğun, bu rutinleri tamamlamada bağımsızlaştığı saptanmıştır. Bunun yanı sıra ilgili sınıftaki öğretmenin, rutinleri hatırlatmak için kullandığı ipuçlarının da azaldığı tespit edilmiştir. Tüm bunlar bir arada değerlendirildiğinde, rutinleri eğitim ortamı içerisinde uygulanabilecek etkili öğrenme stratejileri olarak düşünmek mümkündür.

Birçok sınıf rutini, açık bir davranışı yönlendirmek için tasarlanırken, düşünme rutinleri de zihinsel eylemi yönlendirmeye yardımcı olmaktadır (Ritchhart ve diğerleri, 2006). Etkili öğretmenler, çocukların düşünmelerini ilerletmelerinde ve öğreniminde güçlü aracılardır. Öğretmenler küçük çocukları düşünme hakkında düşünmeye ve konuşmaya davet ettiklerinde, küçük çocukların düşüncelerinin egosantrik ve somut yönüyle karşı karşıya kalırlar. Erken çocukluk yıllarında çocukların düşüncelerinin somut yapısı, öğretmenlerin çocukların düşünme süreçlerini desteklemeleri konusunda oldukça çaba sergilemesi gerekliliğini doğurmaktadır. Çünkü düşünmeye ilişkin en temel problemlerden biri olan düşünmenin görülmez olması, bir diğer ifade ile düşünmenin bu anlamda somut olmaması, erken çocukluk eğitim ortamları içerisinde düşünme süreçlerinin desteklenmesinde yeni arayışlara yöneltmiştir (Salmon, 2010). Düşünme Rutinleri bu noktada çocukların merakını tetikleyen öğrenme ortamları tasarlama ve eğitim programı yoluyla düşünmeyi kışkırtma ve üst bilişsel (düşünme hakkında düşünme) etkinlikleri teşvik etme açısından öğretmenler için oldukça avantajlı rutinlerdir (Salmon, 2010). Tablo 1'de bazı Düşünme Rutinlerine detaylı olarak yer verilmiştir (Visible Thinking, 2018).

Tablo 1. Düşünme rutinleri ve açıklamaları

\begin{tabular}{|c|c|}
\hline Düşünme Rutinleri & Açıklamalar \\
\hline $\begin{array}{l}\text { Bunu Neden } \\
\text { Söylüyorsun? }\end{array}$ & $\begin{array}{l}\text { Gerekçeleri ile yorumlama: } \\
\text { • Burada ne oluyor? } \\
\text { • Bunu ne gördüğün için söylüyorsun? }\end{array}$ \\
\hline Düşün/Bul/Keşfet & $\begin{array}{l}\text { Daha derin sorgulama yapmak için ortam hazırlama: } \\
\text { - Bu konu hakkında ne düşünüyorsunuz? } \\
\text { - Bu konu hakkında neleri merak ediyorsunuz/Neler sizin için bilinmez? } \\
\text { - Bu konuyu nasıl keşfedebilirsin? }\end{array}$ \\
\hline Düşün/Eşleş/Paylaş & $\begin{array}{l}\text { Aktif düşünme ve açıklama: } \\
\text { • Çocuklara bir soru sormayı, } \\
\text { • Düşünmeleri için birkaç dakika süre vermeyi, }\end{array}$ \\
\hline
\end{tabular}




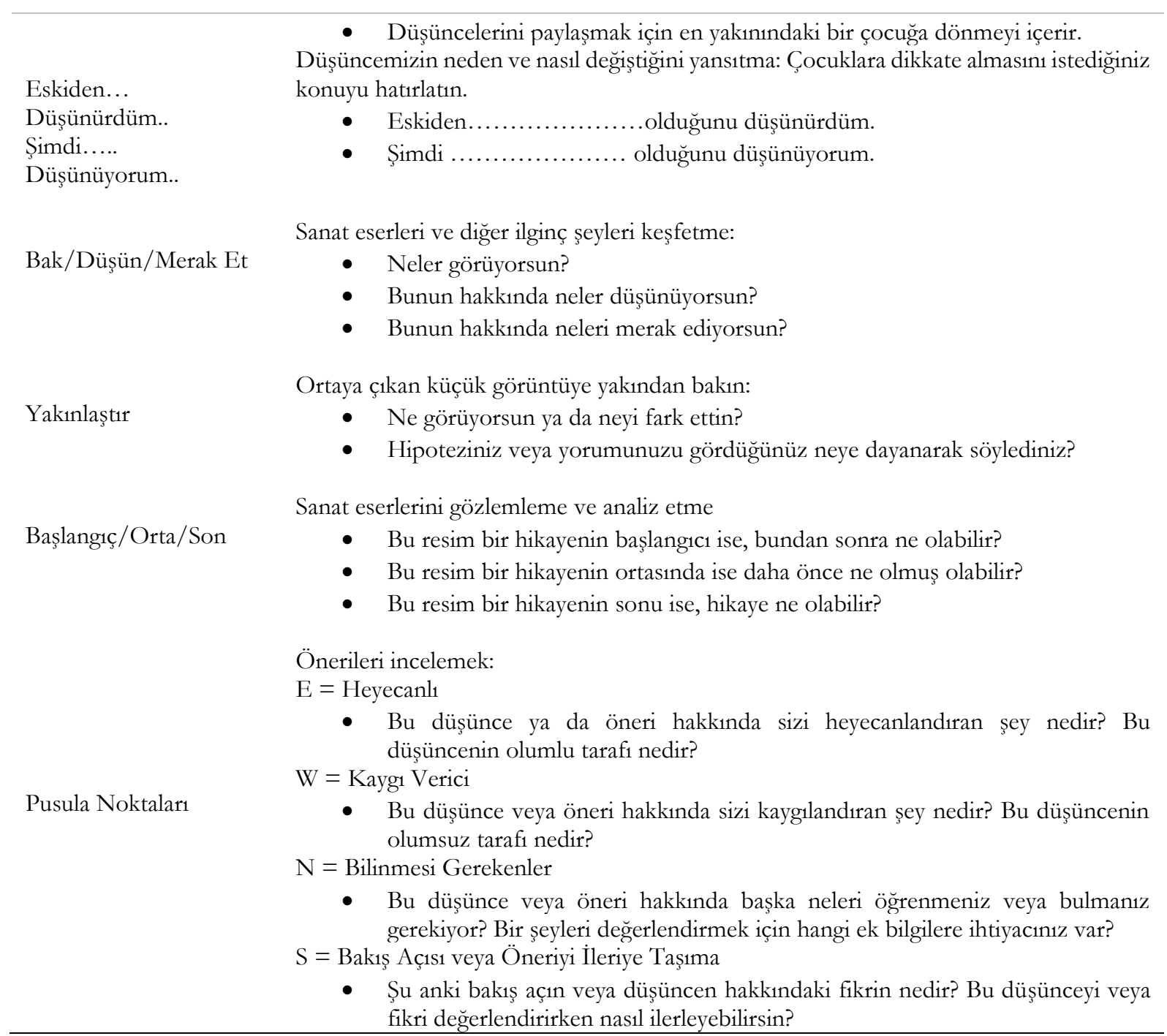

Düşünme rutinleri ve belgeleme, çocukların kendi bilişsel gelişimlerini, yaratıcı düşüncelerinin ve problem çözme becerilerinin farkına varmalarına yardımcı olarak geliştirilen araçlardır. Düşünme rutinlerinin kullanılması ve gelişimsel açıdan yaşa uygun olarak düzenlenmesi kolaydır; sadece çocukların ön bilgilerini etkinleştirmekle kalmaz, aynı zamanda düşüncelerini de genişletirler. Bu rutinlerin esnek oluşu, ögretmenlerin düşünme yöntemlerini küçük çocuklar için kullanmalarına olanak tanır. Küçük çocukları düşünmeyi düşünmeye zorlayan güçlüklere rağmen, düşünme rutinleri, öğretmenlere, değerlendirmede ve günlük eğitim akışının planlamasında kullanabilecekleri yeni araçlar sağlar (Salmon, 2010). Düşünme rutinleri tekrarlanan uygulamalarla sınıf kültürünün bir parçası haline geldiğinde, çocuğun entelektüel karakterinin bir parçası haline gelen düşünme ve öğrenme kalıpları yaratırlar (Ritchhart, 2002).

Tüm diğer öğrenme araçlarında olduğu gibi, öğretmenler, düşünme rutinlerinin kullanımının da hedeflenen kazanımlara ulaşılmasındaki etkililik düzeyini değerlendirebilmelidirler. Örneğin öğretmenlerin, bir rutini kullandıktan sonra, bu rutinin, çocukların ilgili kazanıma ulaşmalarında ne 
kadar etkili olduğu, derin öğrenmeye yardımcı olup olmadığı, çocukların anlayışlarını geliştirmelerine katkı sağlayıp sağlamadığı, ilgili rutinin bir sonraki kullanımında yeniden düzenlenip düzenlenmemesi gerekliliği, gerekli ise bir sonraki kullanımda hangi basamağına daha fazla zaman verilmesi gerektiği ve çocukların bu rutini ileride bağımsız olarak kullanıp kullanamayacakları gibi sorular üzerinde düşünmelerini ve çeşitli yargılarda bulunmalarını gerektirmektedir (Ritchhart, 2015, s.194).

Düşünme Rutinleri'nin amaçladığ1 yapıya ulaşmasında önemli basamaklardan biri rutinlerin çocuklara sunulması sırasında çocukların meraklarını kışkırtacak sembollerin (görseller gibi) sunulması ve soruların yöneltilmesi, diğeri ise ilgili rutinlerin uygulanması sırasında çocuklardan toplanacak ürünlerin ve kanttların belgelenmesidir. Rinaldi'ye (1994) göre, çocukların ürünlerini belgeleme, onları gerçek anlamda dinlemenin, onlara kulak vermenin görünür bir şekle bürünmesini ifade etmektedir. Belgeleme, oldukça dar anlamıyla, sınıfta neler olduğuyla ilgili kanıt ve eser toplama sürecidir. Rinaldi (1994) ayrıca, "belgelerin yalnızca kanıt ve insanlar tarafindan yapılmıs ürün toplama sürecini değil, aynı zamanda fiziksel bir kanıt ve ürün koleksiyonu, koleksiyonun neyi yansıttığ1 ve analizi ve bu koleksiyonun ya da onun bir parçasının sunumu” olduğunu düşünmekte, belgelemenin çocukların, öğretmenleri, aileleri ve diğer kişiler için görünür olmalarını sağlayan yol olduğunu savunmaktadır. Belgeleme yolu ile (çocuklar tarafindan oluşturulan çizimler, sorulan sorular, etkileşimler sırasında girilen diyaloglar, oluşturulan grafikler, şekiller, 3-boyutlu yapılar, fotoğraf, film, ses kayıtları ve notlar vasıtasıyla) çocukların deneyimlerini, düşüncelerini ve fikirlerini anlamak ve öğrenme süreçlerini sergilemek mümkün olmaktadır (Fernández Santín ve Torruella, 2017). Görünür Düşünme Yaklaşımı'nda belgeleme sürecinin anlamlı yürütülebilmesi için birtakım temel ilkelerin izlenmesi gerekmektedir. Bunlar (Perkins, 2003, s. 13):

- Belgeleme, genellikle epistemolojik bir odakla (öğrenme sorularına odaklanmak) süreci yönlendiren özel bir soruyu içerir.

- Belgeler, bireysel ve grup gözlemlerini toplu olarak analiz etmek, yorumlamak ve değerlendirmekle ilgilidir; çoklu bakış açısı ile güçlendirilmiştir.

- Belgeleme çoklu dil (çeşitli araç ve sembol sistemlerinde düşünmeyi temsil ve ifade etmenin farklı yolları) kullanımıyla gerçekleştirilir.

- Belgeleme öğrenmeyi görünür kılar; gizli değildir. Belgeler, bu süreci tamamlayan çocuklar ile paylaşıldığında; diğer çocukların, ebeveynlerin veya öğretmenlerin incelemesi için açık hale getirilir.

- Belgeleme sadece geçmişe yönelik (retrospektif) değil, ileriye dönüktür. Etkili ve derin öğrenme için gelecekteki bağlamların tasarımını şekillendirir. 


\section{Düşünme Rutinleri Uygulama Örnekleri}

Bunu Neden Söylüyorsun? Rutini; çocukların gözlemlediklerini veya sahip oldukları bilgileri tanımlamalarını sağlamaktır. Aynı zamanda, çocukları kanıta dayalı akıl yürütmeye ve çocukların yorumlarını paylaşmalarını sağladığından alternatifleri ve çoklu bakış açılarını anlamaya teşvik etmektedir. Bu rutinde öğretmen tarafindan yöneltilebilecek sorular esnek olduğu için, sanat eserleri ya da tarihi eserler gibi nesneler incelenirken kullanışlı olabilir. Aynı zamanda bir şiiri keşfetmek, bilimsel gözlemler yapmak, hipotez kurmak ya da daha kavramsal fikirleri araştırmak için de kullanılabilir (Örneğin, demokrasi). Rutin hemen hemen her tema/kavramın kazandırılması için uyarlanabilir ve aynı zamanda yeni bir tema/kavram sunarken çocukların genel düşünceleri hakkında bilgi toplamak için de yararlı olabilir. Rutin çoğu durumda, bir nesne veya tema/kavram etrafinda sınıfta büyük grup etkinliği ile gerçekleştirilebilir. Ancak küçük gruplar halinde veya bireysel olarak da kullanılabilir. Öğretmen ilk kez rutini tanıtırken, bir çocuk bir yorumda bulunduktan sonra sürekli olarak soruları sorarak çocukları destekleyebilir. Bu rutine ilişkin iki temel soru, içeriğe bağlı olarak çeşitli şekillerde değiştirilebilir: "Burada ne oluyor? Bunu neyi gördügün için söylüyorsun?”. Bazen çocukların düşünceleri bir açıklama sorusu kullanılarak yorumlanabilir: "Ne görüyorsun?" ya da "Ne biliyorsun?" gibi. Bu rutini bir grup sohbetinde kullanırken, tartışmanın akışına müdahale etmeden alternatif dokümantasyon formlarını düşünmek gerekebilir. Video veya ses kaydı kullanarak sınıf tartışmalarını kaydetmek bir seçenek olabilirken, çocukların düşünme dilini kullanıp kullanmadıklarını dinlemek onların gelişimlerini takip etmeye yardımcı olabilir. Bir grafik hazırlamak veya sınıfta konuşulan açıklamaların bir listesini tutmak başka bir seçenek olarak da kullanılabilir. Diğer bir seçenek ise hem grup çalışması hem de bireysel çalışma için çocukların yorumlarını belgeleyen taslaklar, çizimler, modeller ve yazıların diğer çocuklar ile paylaşılmasıdır (Visible Thinking, 2018). Bu rutini uygulamak isteyen bir öğretmen, örneğin, "Kalebozan Karlo"1 hikaye kitabının ilk sayfasını çocuklara okur. İkinci sayfasının renkli fotokopisini alarak bir fon kartonunun üzerine yapıştırır. Çocuklara "Burada ne oluyor? Bunu ne gördüğün için söylüyorsun?” sorularını sorar. Çocukların cevaplarını karton üzerine yapışkan kağıtları kullanarak yapıştırır. Etkinlik bitiminde çocuklarla birlikte düşünceleri değerlendirilir (Bkz. Şekil 1).

\footnotetext{
${ }^{1}$ Montanari, E. (2006). Kalebozan Karlo, Redhouse Kidz Yayınları. 


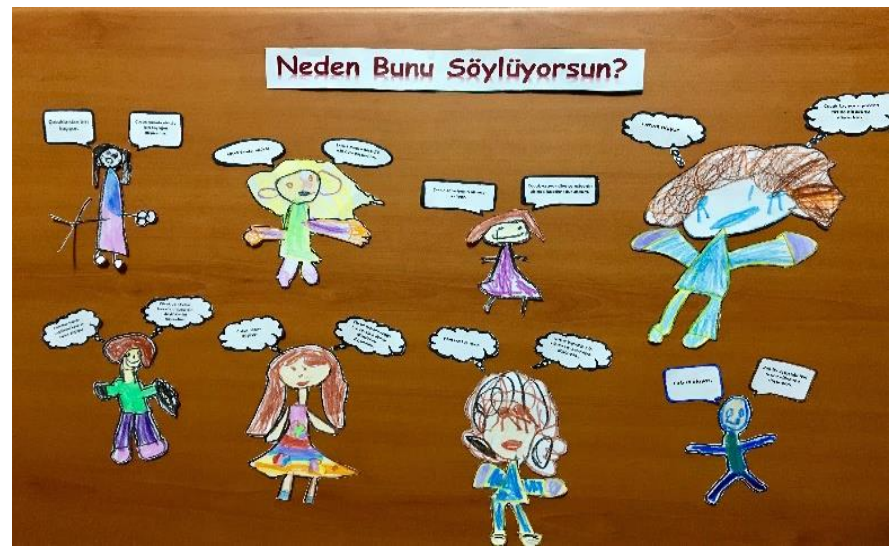

Ç2: "Cocuk bağırdı̆̆ için yılanın kıı̨ kaçırdiğmı düsündüm”.

Ç3: "Çocuk kaçyor o yüzden firtına olduğunu düsündüm".

Ç5: "Çocuk havada olduğu için kaçtı̆ğm düşündüm".

Şekil 1. Bunu Neden Söylüyorsun? Rutini

Düşün/Bul/Keşfet Rutini; çocukların önceki bilgileri ile bağlantı kurmalarını sağlamada, merak uyandırmada ve bağımsız sorgulama için temelleri hazırlama amacıyla kullanılmaktadır. Bir tema/kavram kazandırmaya başlanıldığında ve çocukların kendi araştırma sorularını geliştirmeleri istediğinde bu rutin etkilidir. Rutinde tema/kavram sunulduktan sonra çocuklara birkaç dakika sessiz an verilerek başlanır. Daha sonra, üç aşamadaki sorular ile ilgili beyin firtınası fikirleri tüm sınıf veya küçük gruplar halinde çalışılabilir. Çocukların fikirlerini düşünmeleri ve ifade etmeleri için her soru arasında yeterli zaman verildiğinden emin olunmalıdır. Bu rutin kullanılmaya başlanıldığında, ilk önce "Düşün- Bu konu hakkında ne düşünüyorsunuz?" ve "Bul- Bu konu hakkında neleri merak ediyorsun?” sorularını birlikte kullanmak gereklidir. Düşünceler ve merak edilenler paylaşıldıktan sonra "Keşfetme- Bu konuyu nasıl keşfedebilirsiniz?" sorusuna geçilebilir. İlginç bir soru kullanılabilir ve seçilen soruları araştırmak için stratejiler tartışlabilir. Çocuklar rutinin başlangıcında basit düşünce ve sorularını listeleyebilirler. Bu durumda çocukların gerçekten şaşırtıcı veya ilginç olan şeyleri düşünmeleri desteklenmelidir. Bir grup ile çalışllyorken, çocuklardan düşüncelerini paylaşmaları sağlanarak grafik üzerinde resim veya tema/kavram hakkında geniş bir fikir listesi oluşturulabilir (Visible Thinking, 2018). Bu rutini uygulamak isteyen bir öğretmen, örneğin, "Mıknatıs konusu hakkında ne düşünüyorsun?" sorusunu çocuklara sorabilir.

Düşün/Eşleş/Paylaş Rutini; çocukları bir problem, soru ya da konu üzerine düşünmeye teşvik eder ve sonra düşüncelerini ifade etmelerini sağlar. Böylelikle çocukların çoklu bakış açılarını anlamalarını sağlayarak etkin akıl yürütme ve açıklama yoluyla anlayışlarını geliştirir. Düşün/Eşleş/Paylaş rutini sınıfta herhangi bir anda uygulanabilir. Örneğin, bir problemi çözerken, bir çözüme yaklaşırken, bir deneyden önce ya da bir kitabın bir bölümünü ya da tamamını okuduktan sonra, çocuklara belirli bir soru ya da sorun hakkında düşünmek için bir dakika zaman verip diğer çocuklara dönmeleri ve düşüncelerini paylaşmaları istenir. Bu paylaşım küçük gruplar halinde yapılabilir. Çocuklara rutini tanıtırken ilk olarak sıra ile konuşmaları, birbirlerini dikkatlice 
dinlemeleri ve birbirleriyle ilgili sorular sormaları gerektiğini hatırlatmak gereklidir. Çocukların birbirlerini dinlemelerini sağlamanın bir yolu, çocukların kendi düşüncelerini açıklamaları yerine, eşleştikleri kişinin düşüncelerini açıklamaya davet etmeleridir. Çocukların düşüncelerini paylaşmadan önce ve/veya paylaştıktan sonra düşüncelerini çizmeleri istenerek sınıftaki tüm fikirlerin bir listesi oluşturabilir (Visible Thinking, 2018). Bu rutini uygulamak isteyen bir öğretmen, örneğin, çocuklara “Okulumuzun daha yeşil olabilmesi için neler yapabiliriz?” sorusunu sorabilir.

Eskiden...olduğunu düşünürdüm. Şimdi...olduğunu düşünüyorum Rutini; çocukların bir tema/kavram hakkındaki düşüncelerini yansıtmalarına ve bu düşüncenin nasıl ve neden değiştiğini araştırmalarına yardımcı olur. Çocuklar düşüncelerinin nasıl ve neden değisstiğini inceleyerek ve açılayarak, akıl yürütme becerilerini geliştirirler ve neden-sonuç ilişkisi kurabilirler. Bu rutin, çocukların ön düşüncelerinin, görüşlerinin veya inanışlarının, eğitim veya deneyim sonucunda uğradığı değişimi incelemek için kullanılabilir. Örneğin yeni bir bilgi, bir film izlemek, bir konuşmacının dinlenmesi, yeni bir şey yaşamak, sınıf tartışması yapmak gibi. Bu rutine başlarken çocuklara, bu etkinliğin amacının tema/kavram hakkındaki fikirlerini düşünmelerine yardımcı olmak ve fikirlerinin zaman içinde nasıl değiştiğini tanımlamak olduğu açıklanmalıdır. Çocukların düşüncelerindeki değişimlerini paylaşmaları ve açıklamaları sağlanmalıdır. Bu rutini başlangıçta bütün bir sınıf ile yapmak daha uygundur. Çocuklar düşüncelerini açılamaya alıştıklarında, birbirleriyle küçük gruplar veya çiftler halinde paylaşabilirler. Rutinde ilk olarak “ hakkında düşünmeye başladığımızda bununla ilgili hepimizin bazı fikirleri ve nın ne olduğu ile ilgili düşünceleri vardı. Şimdi birkaç cümleyle, bunun hakkında ne düşündügünüzü yazmak istiyorum. Tekrar bunun için düşünün ve daha önce bunun hakkında ne düşündüğünüzü söyleyin. "Eskiden olduğunu düşünüyordum” yönergesi ile çocukların düşünceleri not edilir. Daha sonra "Şimdi, çalışmakta olduğumuz / yaptığımız / tartıştığımızın bir sonucu olarak hakkındaki düşüncelerinizin nasıl değiştiğini düşünmenizi istiyorum. Yine sadece birkaç cümleyle, şimdi ne düşündügünüzü söyleyin Cümlelerinize "Ama şimdi, bence ile başlayın" yönergesi ile çocukların değişen düşünceleri alınır (Visible Thinking, 2018). Bu rutini uygulamak isteyen bir öğretmen, örneğin, çocukların tırtılın kelebeğe dönüşümüne ilişkin ön bilgilerini alır. Çocukların bu konudaki fikirlerini not alır. Tirtılın kelebeğe dönüşümüne ilişkin bir belgesel izletir ve belgesel üzerine çocukların önceki bilgileri, fikirleri tartışllır.

Bak/Düşün/Merak Et Rutini; çocukları dikkatli gözlem yapmaya ve çeşitli fikirler ile yorumlar yapmaya teşvik eder. Aynı zamanda merak uyandırmaya yardımcı olur ve çocukları sorgulama aşamasına hazırlar. Bu rutin çocukların bir şeyin neden böyle göründüğüne ya da olduğuna dikkat 
etmeleri istenildiğinde kullanılabilir. Rutin çocukları yeni bir temanın/kavramın başlangıcında ya da yeni bilgi ve düşüncelerini daha fazla uygulamaya teşvik etmek için bir temanın/etkinliğin sonuna yakın ilginç bir nesne ile kullanılabilir. Rutinin uygulanmasına başlarken çocuklardan bir nesne, bir sanat eseri ya da imgeyi gözlemlemeleri istenir. Çocuklara "Neler görüyorsun?” sorusu sorularak, çocukların düşüncelerini nedenleri ile birlikte paylaşmaları teşvik edilir. Daha sonra çocuklardan, nesne ya da resim hakkında merak ettiklerini düşünmeleri istenir. Rutin, üç aşama aynı anda birlikte kullanıldığında en verimli şekilde sonuç verecektir. "Ben görüyorum. Bence . Ben merak ediyorum" gibi. Rutin bir grup tartışmasında etkili olabilir, çocukların verdikleri yanıtlar yazılabilir ve kaydedilebilir (Visible Thinking, 2018). Bu rutini uygulamak isteyen bir öğretmen, örneğin, çocuklara "Malena'nın Aynası"' hikaye kitabından bir sayfa gösterir. Sonra sırasıyla "Neler görüyorsun?”, "Bunun hakkında neler düşünüyorsun?”, "Bunun hakkında neleri merak ediyorsun?” sorularını sorar. Çocukların cevaplarını karton üzerine yapışkanlı kağıtlara yazarak yapıştırır. Çocuklarla birlikte düşünceleri değerlendirilir (Bkz. Şekil 2).

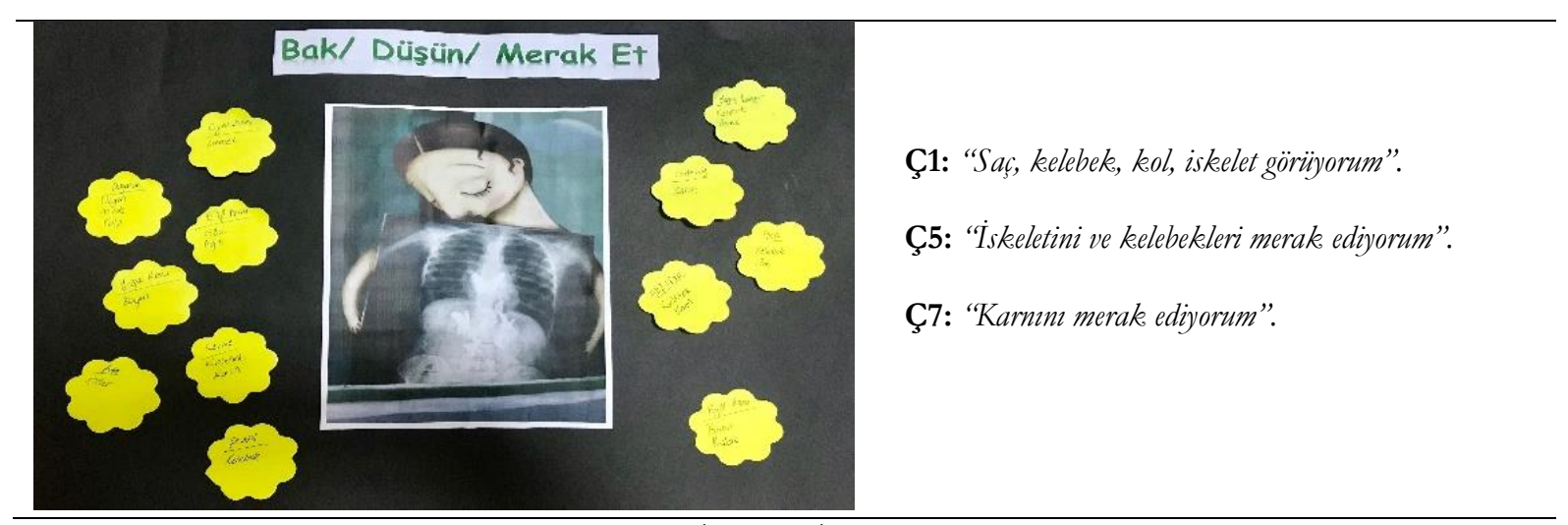

Şekil 2. Bak/Düşün/Merak Et Rutini

Yakınlaştır Rutini; çocuklardan bir görüntünün bir kısmını yakından gözlemlemelerini ve buna ilişkin bir hipotez geliştirmelerini sağlar. Rutinde yeni görsel bilgiler sunuldukça çocukların görsele yeniden yakından bakması ve başlangıçtaki yorumunu yeni bilgiler ışı̆̆ında yeniden gözden geçirmesi istenir. Bu rutin bireysel, küçük grup ya da büyük grup etkinliği olarak gerçekleştirilebilir. Rutinde, resmin bir parçasının üstünü açarak daha fazlası ortaya çıkarılır ve çocuklardan gördükleri yeni bir şeyi bulmaları istenir. Bu yeni bilgilerin önceki düşünce ve hipotezlerini nasıl etkilediğini düşünmeleri istenir. Bu sırada ortaya çıkan küçük görüntüye yakından bakmaları söylenir ve " $\mathrm{Ne}$ görüyorsun ya da neyi farkettin?”, “Hipoteziniz veya yorumunuzu gördügünüz neye dayanarak söylediniz?”, “Sence bu iki insan arasındaki ilişki ne olabilir?”, "Bir sonraki bölümün nasıl görüneceğine dair bir tahmininiz var mı?” soruları sorulabilir. Resmin tamamı ortaya çıkana kadar yorumlama sürecine devam edilir. Süreç boyunca çocuklar ile tartışmalar devam eder. Çocukların

${ }^{1}$ Ferrandiz, E. (2017). Malena'nın Aynası. Yapı Kredi Yayınları. 
düşünce ve yorumlarının zaman içinde nasıl değiştiğini düşünmeleri istenir. Bu sırada "Resmin daha fazlasını görmek düşüncelerinizi nasıl etkiledi?”, "Hangi parçalar özellikle bilgi bakımından daha zengin ve belirgindi?” ve "Hangi parçalar belirsizdi?” soruları sorulabilir (Ritchhart, Church ve Morrison, 2011). Bu rutini uygulamak isteyen bir öğretmen, örneğin, ressam Jean-François Millet'in 1857'de yaptığı Başak Toplayan Kadınlar/Köylüler (Des glaneuses) isimli resminin tamamını yapboz parçaları ile kapatır. Her defasında resmi örten yap-boz parçalarından biri açılarak ilgili sorular çocuklara sorulur.

Başlangıc/Orta/Son Rutini; çocukların basit rutinler ile sanat eserlerini gözlemleyerek ve analiz ederek hayal güçlerini kullanmaya teşvik eder ve onlara eleştirel düşünmeyi öğretir. Rutin yeni bir tema/kavramın başlangıcında ya da etkinliğin sonuna yakın, resim veya heykel gibi her türlü görsel sanat eseri ile kullanılabilir. Rutinde çocukların bir sanat eserini gözlemleyerek bir dakika geçirmeleri ve kendi başlanna resimde neler olup bittiğini düşünmeleri istenir. Sonra çocukların düşüncelerini bir arkadaşları ile paylaşmaları ve ardından tartışmayı tüm gruba açmaları sağlanır. Bir çocuk düşüncesini paylaştı̆̆ında, çocuğa resimde bu düşüncesini destekleyen ne gördüğü sorulur. Önemli ayrıntılar ve birkaç farklı yorum paylaşıldıktan sonra, çocuklara "Bu resim/görüntü bir hikayenin başlangıcı ise, bundan sonra ne olabilir?”, "Bu resim/görüntü bir hikayenin ortasında ise daha önce ne olmuş olabilir?”, "Bu resim/görüntü bir hikayenin sonu ise, hikaye ne olabilir?” soruları sırasıyla sorulur ve düşünmeleri istenir. Rutin bir grup tartışmasında etkili olabilir, çocukların verdikleri yanıtlar yazılabilir ve kaydedilebilir (Project Zero, 2018). Bu rutini uygulamak isteyen bir öğretmen, örneğin, Ressam Pierre-Auguste Renoir'ın “The Umbrellas” isimli eserini çocuklara gösterir. Çocuklara "Bu resim/görüntü bir hikayenin başlangıcı ise, bundan sonra ne olabilir?" " $\mathrm{Bu}$ resim/görüntü bir hikayenin sonu ise, hikaye ne olabilir?” soruları sırasıyla sorulur. Çocukların cevapları yapışkan kağıtlara yazılır. Çocuklarla birlikte düşünceleri değerlendirilir (Bkz. Şekil 3). 


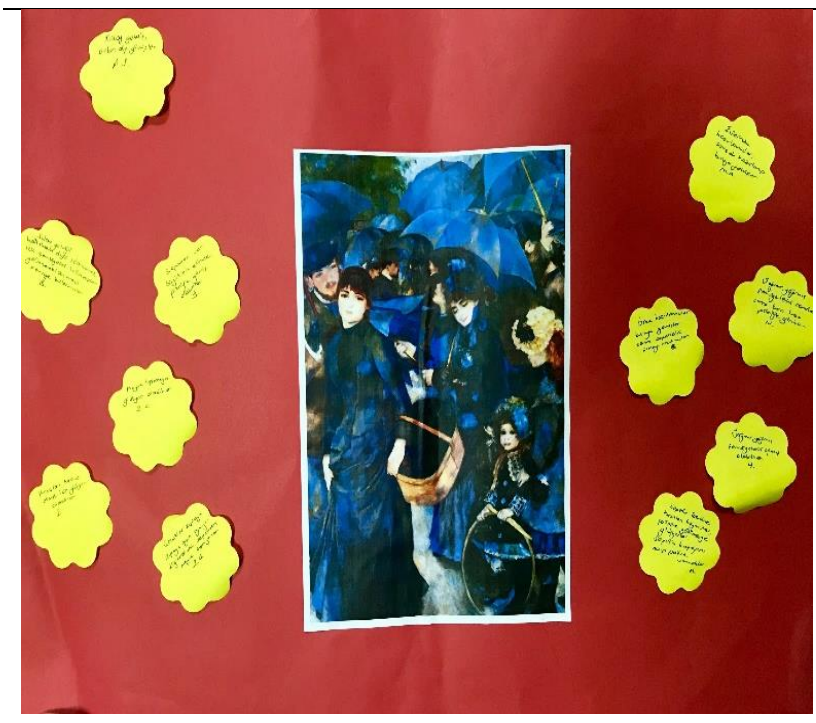
Bu resim bir hikayenin başlangıcı ise, bundan sonra ne olabilir?"
Ç1: "Sepetler var büyüklerin ellerinde pikniğe gitmiş olabilirler".
Ç3: "Cocuklar żplaya żplaya oyun oynuyorlar diğerleri de sepetten meyve topluyorlar".
Ç5: "Sularn geldiği belli olmasın diye islanmamak için mavi şemsiyeleri kullanmışlar".
Bu resim bir hikayenin sonu ise, hikaye ne olabilir?"
Ç2: "Evlerinde hažrlanmıslar, giyinmişler sonra da buraya gelmisler".
Ç4: "Y ağmur yağmıs șemsiyelerini açmıșlar, sonra koșa koșa piknik yapmaya gitmisler".
Ç7: "Sepetin içerisine hırsızlar koymuslar, polislere götürmeye gidiyorlar. Sepetin kapağm açıp polislere teslim etmisler".

Şekil 3. Başlangıç/Orta/Son Rutini

Pusula Noktaları Rutini; çocukların düşünce ya da önerilerini ayrıntılarıyla anlatmalarına ve sonuçlarını değerlendirmelerine yardımcı olur. Bu rutin, bir duruş ya da bir görüş bildirmeden önce bir öneri ya da fikrin çeşitli taraflarını ve yönlerini araştırmak için kullanılabilir. Örneğin, okula yeni kıyafet kuralı getirme ya da öğretmenin sınıftaki eşyaların yerini değiştirme fikri çocuklara sunulabilir. Rutinin başlangıcında tüm grubun görmesi için kaydedilen cevaplarla tüm gruba model olunmalıdır. Bu, çocukların birbirlerinin fikirlerini geliştirmelerine olanak tanıyacaktır. Görsel bir bağlantı sağlamak için bir pusulanın yönlerini kullanarak yanıtlar kaydedilebilir. Yani, tahtanın ortasına bir pusula çizilir ve daha sonra uygun yöne karşılık gelen cevaplar kaydedilir. Çocukların fikir ya da öneri verirken heyecan verici ya da olumlu olanlarla $(E=$ Heyecanlı: Bu düşünce ya da öneri hakkında sizi heyecanlandıran şey nedir? Bu düşüncenin olumlu tarafı nedir?) başlaması genellikle en kolay olanıdır. Sonra pusulanın W (Kayg1 verici) yönü geldiğinde "Bu düşünce veya öneri hakkında sizi kaygılandıran şey nedir? Bu düşüncenin olumsuz tarafı nedir?”; N (Bilinmesi gerekenler) yönü geldiğinde "Bu düşünce veya öneri hakkında başka neleri öğrenmeniz veya bulmanız gerekiyor? Bir şeyleri değerlendirmek için hangi ek bilgilere ihtiyacın var?” ve S (Bakış Açısı veya Öneriyi İleriye Taşıma) yönü geldiğinde "Şu anki bakış açın veya düşüncen hakkındaki fikrin nedir? Bu düşünceyi veya fikri değerlendirirken nasıl ilerleyebilirsin?” soruları sorulur. Çocuklardan, düşünce veya önermelerinin ilk değerlendirmesini yapmaları istenir ve daha sonra pusula noktalarını kullanarak tartışmaların ardından düşüncelerinin nasıl değiştiği sorulabilir (Visible Thinking, 2018). Bu rutini uygulamak isteyen bir öğretmen, örneğin, çevre kirliliğine ilişkin bir görsel resim kullanarak çocuklar ile birlikte pusula noktalarına göre tartısma başlatabilir. 


\section{SONUÇ ve ÖNERİLER}

Düşünmenin öğretilmesi, Dünya eğitim tarihinin öne çıkan konu başlıklarından birisi olmaya devam etmektedir. Farklı kuramsal yapılar temel alınarak, düşünmenin çok boyutlu yapısı farklı boyutları ile çeşitli eğitsel uygulamalarla test edilmeye devam etmektedir. Türkiye'de ise, özellikle son yıllarda, erken çocukluk döneminde düşünme becerilerinin gelişimine (Dağlığlu ve Çakır, 2007; Koyuncu Şahin ve Akman, 2018), düşünme gelişiminde etkili olan öğretim yöntemlerine (Tuğrul, 2006), düşünme becerileri konusunda öğretmen görüşlerine (Doğan Altun ve Ekinci Vural, 2017; Mutlu ve Aktan, 2011) ve uygulamalarına (Büyüktaşkapu Soydan ve Dereli, 2014) yönelik çalışmaların hız kazandığı görülmektedir. Doğan Altun ve Ekinci Vural (2017) tarafindan gerçekleştirilen nitel araştırmada, çalışmaya dahil olan öğretmenlerin düşünme becerilerinin gelişimi için eğitim-öğretim ortamının, sosyal etkileşimin ve fiziksel çevrenin etkili olduğunu düşündükleri tespit edilmiştir. Ayrıca düşünme becerilerinin geliştirilmesinde, öğretmenin rehber ve model olduğu, çocukların düşüncelerini özgürce paylaşabildikleri ve öğrenme süreçlerinde aktif rol aldıkları bir sınıf ortamının oluşturulmasının önemli olduğunu düşündükleri ortaya çıkmıştır. Ancak son yıllarda, okul öncesi öğretmenleri ve öğretmen adayları ile gerçekleştirilen öğretmen alg1sı araştırmalarında (metafor çalışmaları), öğretmenlerin ve öğretmen adaylarının "öğretmen”i tanımlarken ilk sırada "koruyan öğretmen” (Küçükturan ve Kocaman, 2017), “şekil veren, yön veren, eksikleri görüp düzelten varlık olarak öğretmen" (Koçer, Ünal ve Eskidemir Meral, 2015) ve "ihtiyaçları karşılayan öğretmen” (Akgün, 2016) olarak sinıflandırılabilecek kategorilere uygun cevaplar verdikleri saptanmıştır. İlgili kategoriler birlikte yorumlandığında, öğretmenlerin ve öğretmen adaylarının, öğretmenlik rollerini tanımlarken ilk sırada "yansıtıcılık” rolünden uzak cevaplar verdiklerini söylemek mümkündür. Tuğrul'a (2006) göre eğitimin amac1 çocuklara bilgi, duygu ve düşünce aktarımı değil, bilgi, duygu ve düşünceleri oluşturma, kullanma ve öğrenmeye karşı güdülenmiş merak ve olumlu tutumlar geliştirmektir. Bu düşünceye paralel olarak çocuklarda düşünme eğilimini, çocukların meraklarını kışkırtacak materyaller, süreçler ve diyaloglarla (Örneğin, soru sorma) pekiştirmenin mümkün olduğu bilinmektedir. Bu noktada çocuklarla çalışan kişilere ve öğretmenlere, düşünmenin görünür olmasını hedefleyen, kısa, tekrarlanabilir, esnek mini stratejiler olan Düşünme Rutinleri’ni, birer düşünme aracı olarak tanıtmanın ve bu rutinlerin kullanımlarına ilişkin örnek uygulamalar sunmanın, çocuklarda düşünme eğilimi oluşturmanın yanı sıra öğretmenlerin "yansıtıcı” olma özelliklerine katkı sağlama durumuna ilişkin zengin deneysel modellerle sunulmuş araştırma bulgularına ihtiyaç duyulmaktadır.

Düşünme Rutinleri'nin hedeflediği yapıya ulaşmasında belgelemenin önemli olduğuna vurgu yapılmıştır. İlgili belgeleme sayesinde hem öğretmen hem çocuklar, hem de aileler çocukların 
düşünme süreçlerini detaylı bir şekilde izleyebilmektedir. Bu detaylı gözlem, gelecek öğrenmelerin ve kazanımların temelini oluşturması bakımından oldukça değerlidir. Türkiye'de okul öncesi öğretmenlerinin çocukları izleme ve değerlendirme uygulamaları ile ilgili oldukça sınırlı olan araştırmalar, öğretmenlerin portfolyo kullandıklarını ancak düşünme becerilerini geliştirmek için portfolyoları kullanmadıklarını ortaya koymaktadır: Sezer (2010), 106 okul öncesi öğretmeni ile gerçekleştirdiği araştırmada, öğretmenlerin \%91’inin portfolyo değerlendirmesi yaptı̆̆ını ifade ettiğini bildirmiştir. Ancak Büyüktaşkapu Soydan ve Dereli (2014) farklı ülkelerde Reggio Emilia yaklaşımının uygulandığı okullarda görev yapan öğretmenlerle gerçekleştirdiği nitel araştırmada, Türkiye'de görev yapan 10 öğretmenin düşünme becerilerini geliştirmek için dokümantasyondan faydalanma stratejisini kullanmadıklarını tespit etmiştir. Görünür Düşünme Yaklaşımı'nda belgeleme süreci, düşünmenin soyut yapısını ortadan kaldırılması ve düşünmenin görünür kılınması bakımından yaklaşımın temel yapıtaşını oluşturmaktadır. Bu bağlamda, öğretmenlerin Düşünme Rutinleri'ni günlük eğitim akışlarının bir parçası olarak kullanma durumları ile belgeleme/dokümantasyon uygulamalarını sistematik bir şekilde ve çocuğun tüm gelişim alanlarını gözlemlenecek şekilde değerlendirme süreçlerine dahil etme durumları arasındaki ilişkinin incelenmesinin, Düşünme Rutinleri'nin eğitim ortamında kullanımının “etkililik ağına” ilişkin detaylı bir fotoğraf sunacağı düşünülebilir.

\section{KAYNAKÇA}

Akgün, E. (2016). Okul öncesi öğretmen adaylarının “çocuk” ve "okul öncesi öğretmeni” kavramına ilişkin metaforik alg1lar1. Abant İ̃æet Baysal Üniversitesi Eğitim Fakültesi Dergisi, 16(4), 1652-1672.

Aslan, S. (2017). Sınıf öğretmenlerinin düşünme becerisi öğretimine yönelik özyeterlik algılarının çeşitli değişkenler açısından incelenmesi. Pamukkale Üniversitesi Ë̆itim Fakültesi Dergisi, 41(41), 61-73.

Aubrey, C., Ghent, K., \& Kanira, E. (2012). Enhancing thinking skills in early childhood. International Journal of Early Years Education, 20(4), 332-348. https://doi.org/10.1080/09669760.2012.743102.

Bay, N., \& Alisinanoğlu, F. (2012). Okul öncesi eğitimi öğretmenlerine uygulanan soru sorma becerisi öğretim programının öğretmenlerin sorularının bilişsel taksonomisine etkisi. Mersin Eğitim Fakültesi Dergisi, 3(8), 80-93.

Baysal, Z. N., Çarıkçı, S., \& Yaşar, E. B. (2017). Sınıf öğretmenlerinin düşünme becerileri öğretimine yönelik farkındalıkları. Ë̆itimde Nitel Arasttrmalar Dergisi, 5(1), 7-28.

Büyüktaşkapu Soydan, S., \& Dereli, H. M. (2014). Farklı yaklaşımları uygulayan okul öncesi öğretmenlerinin çocuklarda düşünme becerilerini geliştirmek için kullandıkları stratejilerin incelenmesi. Kastamonu Ë̆itim Dergisi, 22(2), 475-496.

Chang, M. (2004). Classroom management in photographs. New York, NY: Scholastic. 
Çakıcı, Y. (2010). Fen eğitiminde yapılandırmacı yaklaşım ve öğrencilerin kavram yanılgıları. Journal of Socıal Scrence, 12(1), 89-115.

Dağlığlu, H. E., \& Çakır, F. (2007). Erken çocukluk döneminde düşünme becerilerinden planlama ve derin düşünmenin geliştirilmesi. Eğitim ve Bilim, 32 (144), 28-35.

De Bono, E. (1991). The direct teaching of thinking in education and the CoRT method. Learning to think: Thinking to learn, 3-14.

Dilekli, Y., \& Tezci, E. (2016). The relationship among teachers' classroom practices for teaching thinking skills, teachers' self-efficacy towards teaching thinking skills and teachers' teaching styles. Thinking Skills and Creativity, 21, 144-151. https://doi.org/10.1016/j.tsc.2016.06.001.

Doğan Altun, Z., \& Ekinci Vural , D. (2017). Okul öncesi dönemde düşünme becerileri: Öğretmen görüşleri. Dokuz Eylül Üniversitesi Buca Eğitim Fakültesi Dergisi, (44), 214-224.

Eggen, P. D., \& Kauchak, D. P. (2006). Strategies and models for teachers: Teaching content and thinking skills. Pearson/Allyn and Bacon.

Fernández Santín, M., \& Feliu Torruella, M. (2017). Reggio Emilia: An essential tool to develop critical thinking in early childhood. Lournal of New Approaches in Educational Research, 6(1), 50-56. http://dx.doi.org/10.13039/501100002809.

Ferrandiz, E. (2017). Malena'nın aynası. Yap1 Kredi Yayınları.

Gardner, H. (1989). Zero-based arts education: An introduction to ARTS PROPEL. Studies in Art Education, 30(2), 71-83. http://dx.doi.org/ 10.1080/00393541.1989.11650706.

Gelman, S. A., \& Frazier, B. N. (2012). Development of thinking in children. K. J. Holyoak ve R. G. Morrison (Ed.), The Oxford handbook of thinking and reasoning (pp. 513-528). New York: Oxford University Press.

Halford, G. S. (2005). Development of thinking. K. J. Holyoak ve R. G. Morrison (Ed.), The Cambridge handbook of thinking and reasoning (pp. 529-558). Cambridge: Cambridge University Press.

Hull, T. H., Balka, D. S., \& Miles, R. H. (2011). Visible thinking in the k 8 mathematics classroom. Corwin Press.

Koçer, H., Ünal, F., \& Eskidemir Meral, S. (2015). Okul öncesi öğretmen adaylarının "çocuk" kavramına ve "öğretmen" kavramına ilişkin metaforlarının öğretmenlik uygulama planlamalarına yansıması. Eğitim ve Ögrretim Araștrmalar Dergisi, 4(1), 171- 185.

Koyuncu Şahin, M., \& Akman, B (2018). Erken çocukluk döneminde düşünme becerilerinin gelişimi. Milli Ë̈̆itim Dergisi, 47(218), 5-20.

Küçükturan, A. G., \& Kocaman, O. (2017). Intercultural investigation of prospective preschool teachers' perceptions of metaphors for child and preschool teacher. Bartn Üniversitesi Egitim Fakültesi Dergisi, 6(3), 1069-1092.

Leinhardt, G., Weidman, C., \& Hammond, K. M. (1987). Introduction and integration of classroom routines by expert teachers. Curriculum Inquiry, 17(2), 135-176. https://doi.org/10.1080/03626784.1987.11075284. 
Montanari, E. (2006). Kalebozan karlo. Redhouse Kıdz Yayınları.

Mutlu, E., \& Aktan, E. (2011). Okul öncesi öğretmenlerinin düşünme eğitimi ile ilgili tutumlarının incelenmesi. Türk Eğitim Bilimleri Dergisi, 9(4), 799-828.

Ostrosky, M. M., Jung, E. Y., Hemmeter, M. L., \& Thomas, D. (2003). Helping children understand routines and classroom schedules. Prepared by the Center on Social and Emotional Foundations for Early Learning. ED 481991.

Öktem, F. (2018). Prof. Dr. Ferbunde Öktem ile düsünme becerileri ve oyun üzerine. 1.12.2018: https://tedmem.org/dosya-konusu/prof-dr-ferhunde-oktem-ile-dusunme-becerileri-oyunuzerine.

Perkins, D., \& Gardner, H. (1988). Why zero: A brief introduction to Project Zero. Journal of Aesthetic Education, 22(1), 7-10.

Perkins, D. (2003). Making thinking visible. Johns Hopkins School of Education: New Horizons for Learning.

Project Zero, (2018). Beginning / Middle / End. 15.10.2018: http://www.pz.harvard.edu/resources/beginning-middle-end.

Rinaldi, C. (1994). Staff development in Reggio Emilia. Lilian G. Katz ve Bernard Cesarone (Ed). Reflections on the Reggio Emilia approach (ss. 55-60). Urbana, IL: ERIC Clearinghouse on Elementary and Early Childhood Education. (Perspectives from ERIC/EECE Monograph No. 6).

Ritchhart, R. (2002). Intellectual character: What it is, why it matters, and how to get it. John Wiley \& Sons.

Ritchhart, R. (2015). Creating cultures of thinking: The 8 forces we must master to truly transform our schools. New York, NY: John Wiley \& Sons.

Ritchhart, R., Palmer, P., Church, M., \& Tishman, S. (2006, April). Thinking routines: Establishing patterns of thinking in the classroom. Paper presented at American Educational Research Association, San Francisco.

Ritchhart, R., \& Perkins, D. N. (2008). Making thinking visible. Educational Leadership, 65(5), 57-61.

Ritchhart, R., Church, M., \& Morrison, K. (2011). Making thinking visible: How to promote engagement, understanding, and independence for all learners. Indianapolis, IN: Jossey Bass.

Rush, J., \& Lovano-Kerr, J. (1982). Project Zero: The evolution of visual arts research during the seventies. Review of Research in Visual Arts Education, 61-81.

Salmon, A. K. (2008). Young English language learners making thinking and language visible. Colombian Applied Linguistics Journal, (10), 126-141.

Salmon, A. K. (2010). Tools to enhance young children's thinking. Young Cbildren, 65(5), 26-31.

Sezer, C. (2010). Okul öncesi ögrretmenlerinin ölçme değerlendirmeyi kullanma düzeylerinin belirlenmesi. Yayınlanmamış yüksek lisans tezi. Çanakkale Onsekiz Mart Üniversitesi, Çanakkale.

Swartz, R. J., \& Perkins, D. N. (1990). Teaching thinking: Issues and approaches. Revised Edition. The Practitioners' Guide to Teaching Thinking Series. Midwest Publications. 
Tebbs, T. J. (2000). Assessing teachers' self-efficacy towards teaching thinking skills (Yayınlanmamış Doktora Tezi). University of Connecticut, Connecticut.

Tuğrul, B. (2006). Okul öncesi dönemde düşünme becerilerinin gelişmesinde yaratıcı bir süreç olarak drama. Yaratıc Drama Dergisi, 1(2), 67-80.

Visible Thinking, (2018). Core routines. $\quad 4.10 .2018$ : http://www.visiblethinkingpz.org/VisibleThinking_html_files/03_ThinkingRoutines/03c_CoreR outines.html.

Watson, K. J., \& DiCarlo, C. F. (2016). Increasing completion of classroom routines through the use of picture activity schedules. Early Childhood Education Journal, 44(2), 89-96. https://doi.org/10.1007/s10643-015-0697-2.

Wildenger, L. K., McIntyre, L. L., Fiese, B. H., \& Eckert, T. L. (2008). Children's daily routine during kindergarten transition. Early Childhood Education Journal, 36(1), 69-74. https://doi.org/10.1007/s10643-008-0255-2.

Woods, J., Kashinath, S., \& Goldstein, H. (2004). Effects of embedding caregiver-1mplemented teaching strategies in daily routines on children's communication outcomes. Journal of Early Intervention, 26, 175-193. https://doi.org/10.1177/105381510402600302.

Wright, A. (2014). Creating a positive classroom culture: Minute by minute. Educational Horizons, 92, 12-15. https://doi.org/10.1177/0013175X1409200405. 